\title{
Seleção de Plantas para Fitorremediação de Solos Contaminados Com Picloram ${ }^{1}$
}

\author{
Plant Selection for Phytoremediation of Soils Contaminated with Picloram
}

CARMO, M.L. ${ }^{2}$, PROCOPIO, S.O. ${ }^{3}$, PIRES, F.R. ${ }^{4}$, CARGNELUTTI FILHO, A. ${ }^{5}$, BARROSO, A.L.L. ${ }^{6}$, SILVA, G.P. ${ }^{6}$, CARMO, E.L. ${ }^{2}$, BRAZ, G.B.P. ${ }^{7}$, SILVA, W.F.P. ${ }^{7}$, BRAZ, A.J.B.P. ${ }^{6}$ e PACHECO, L.P. ${ }^{2}$

\begin{abstract}
RESUMO - Uma das primeiras etapas quando se inicia um programa de fitorremediação de herbicidas é a avaliação da tolerância das espécies vegetais selecionadas ao respectivo contaminante. Registrado para uso no Brasil, o picloram apresenta elevada persistência no solo, podendo causar problemas de carryover e de contaminação de águas subterrâneas. Em decorrência disso, objetivou-se com este trabalho selecionar espécies que apresentem tolerância à presença do picloram no solo, para utilização futura em programas de fitorremediação de solos contaminados com este herbicida. O experimento foi realizado no período de outubro a dezembro de 2005, em casa de vegetação em Rio Verde/GO. Os tratamentos foram compostos pela combinação entre 19 espécies vegetais [Brachiaria brizantha (cv. Marandu); Brachiaria brizantha (cv. MG-5 Vitória); Brachiaria brizantha (cv. Mulato); Brachiaria decumbens; Brachiaria humidicola; Brachiaria ruziziensis; Panicum maximum (cv. Massai); Panicum maximum (cv. Mombaça); Panicum maximum (cv. Tanzânia); Pennisetum purpureum $\mathrm{x}$ Pennisetum glaucum - capim-elefante (cv. Paraíso); Eleusine coracana - capim-pé-de-galinhagigante; Pennisetum glaucum - milheto (cv. ADR-300); Pennisetum glaucum - milheto (cv. ADR500); Sorghum bicolor $x$ Sorghum sudanense - Cover Crop; Sorghum bicolor $x$ Sorghum sudanense - sorgo (cv. Jumbo); Paspalum atratum - capim-pojuca; Zea mays - milho (híbrido Coodetec 208); Canavalia ensiformis - feijão-de-porco; e Stizolobium aterrimum - mucuna-preta] e de cinco doses do picloram $\left(0,80,160,320\right.$ e $\left.640 \mathrm{~g} \mathrm{ha}^{-1}\right)$, totalizando 95 tratamentos. O delineamento experimental utilizado foi o de blocos casualizados em esquema fatorial $19 \times 5$, com quatro repetições. As plantas foram cultivadas em solo classificado como Latossolo Vermelho eutroférrico; após o preenchimento e umedecimento dos vasos, aplicou-se o picloram. Quinze dias após a aplicação do herbicida foi realizada a semeadura das espécies vegetais. Após a análise dos resultados, constatou-se que as espécies Zea mays - milho (híbrido Coodetec 208), Sorghum bicolor $x$ Sorghum sudanense - Cover Crop, Eleusine coracana - capim-pé-de-galinha-gigante, Brachiaria brizantha (cv. MG-5 Vitória), Pennisetum glaucum milheto (cv. ADR-500), Brachiaria decumbens, Brachiaria ruziziensis, Brachiaria humidicola, Pennisetum glaucum - milheto (cv. ADR-300), Brachiaria brizantha (cv. Mulato), Sorghum bicolor $x$ Sorghum sudanense - sorgo (cv. Jumbo), Panicum maximum (cv. Tanzânia), Panicum maximum (cv. Mombaça) e Panicum maximum (cv. Massai) apresentaram tolerância à atividade residual do picloram no solo, podendo ser inseridas inicialmente para avaliação em programas de fitorremediação desse herbicida.
\end{abstract}

Palavras-chave: plantas forrageiras, residual de herbicidas, mimetizadores de auxinas.

ABSTRACT - To initiate a phytoremediation program, the first step is to evaluate the tolerance of selected species to its contaminant. Registered for use in Brazil, picloram may cause carryover and underground water contamination problems due to its high persistence on soil. Thus, this

1 Recebido para publicação em 6.7.2007 e na forma revisada em 20.3.2008.

2 Mestrando do Programa de Pós-Graduação da Fesurv - Universidade de Rio Verde, 75901-970, Rio Verde-GO; ${ }^{3}$ Pesquisador da Embrapa Tabuleiros Costeiros, 49025-040, Aracaju-SE, <procopio@cpatc.embrapa.br>, Bolsista do CNPq; ${ }^{4}$ Professor do Dep. de Ciências da Saúde, Biológicas e Agrárias do Centro Universitário Norte do ES/UFES, 29933-480, São Mateus-ES; ${ }^{5}$ Professor do Dep. de Estatística da UFRGS, 90040-060, Porto Alegre-RS; ${ }^{6}$ Professor da Faculdade de Agronomia da Fesurv Universidade de Rio Verde; ${ }^{7}$ Discente de Agronomia da Fesurv - Universidade de Rio Verde.

Planta Daninha, Viçosa-MG, v. 26, n. 2, p. 301-313, 2008 
work aimed to select species tolerant to picloram in soil contaminated with this herbicide for posterior use in phytoremediation programs. The experiment was carried out in a greenhouse, in Rio Verde-GO, from October to December of 2005. The treatments consisted of combinations of 19 plant species [Brachiaria brizantha (cv. Marandu); Brachiaria brizantha (cv. MG-5 Vitória); Brachiaria brizantha (cv. Mulato); Brachiaria decumbens; Brachiaria humidicola; Brachiaria ruziziensis; Panicum maximum (cv. Massai); Panicum maximum (cv. Mombaça); Panicum maximum (cv. Tanzânia); Pennisetum purpureum $x$ Pennisetum glaucum (cv. Paraiso); Eleusine coracana; Pennisetum glaucum (cv. ADR-300); Pennisetum glaucum (cv. ADR-500); Sorghum bicolor $x$ Sorghum sudanense-Cover Crop; Sorghum bicolor $x$ Sorghum sudanense (cv. Jumbo); Paspalum atratum; Zea mays (hibrid Coodetec 208); Canavalia ensiformis; and Stizolobium aterrimum] and five rates of picloram (0, 80, 160, 320 and $640 \mathrm{~g} \mathrm{ha}^{-1}$ ), in 95 treatments. The experiment was arranged in a randomized block design in a factorial scheme 19 X 5, with four replications. Samples of eutroferric Red Latosol were used as substrate to plant growth, with the herbicide applied after filling and humidifying the pots, and after 15 days, seeds from the plant species were sown. After analyzing the results, Zea mays (hybrid Coodetec 208), Sorghum bicolor $x$ Sorghum sudanense - Cover Crop, Eleusine coracana, Brachiaria brizantha ( $v$. MG-5 Vitória), Pennisetum glaucum (cv. ADR-50O), Brachiaria decumbens, Brachiaria ruziziensis, Brachiaria humidicola, Pennisetum glaucum ( $c v$. ADR-300), Brachiaria brizantha ( $c v$. Mulato), Sorghum bicolor $x$ Sorghum sudanense ( $c v$. Jumbo), Panicum maximum (cv. Tanzânia), Panicum maximum (cv. Mombaça) and Panicum maximum (cv. Massai) showed tolerance to herbicide carryover on soil, thus these species may be initially evaluated in phytoremediation programs of this herbicide.

Keywords: forage, carryover, auxin herbicides.

\section{INTRODUÇÃO}

A técnica conhecida como fitorremediação vem sendo difundida como alternativa de grande interesse, por apresentar possibilidade de remediação in situ de contaminantes inorgânicos e orgânicos no solo e na água (Susarla et al., 2002), ser de baixo custo (Newman et al., 1998) $\mathrm{e}$, ainda, porque as plantas despoluidoras, não raro, resultam em benefícios adicionais além da própria remediação, principalmente quando são leguminosas (Pires et al., 2006).

Ultimamente, no Brasil, estudos com fitorremediação, além do caráter ambiental (Corseuil \& Moreno, 2001; Scramin et al., 2001), têm sido conduzidos em áreas agricultáveis. Esses trabalhos evidenciaram a possibilidade de empregar plantas para reduzir a fitotoxicidade de herbicidas em culturas suscetiveis, implantadas em áreas com resíduos desses produtos (Santos et al., 2007).

Após etapas de seleção, Stizolobium aterrimum (mucuna-preta) e Canavalia ensiformis (feijão-de-porco) foram capazes de reduzir os niveis do herbicida trifloxysulfuronsodium no solo (Santos et al., 2004a; Procópio et al., 2005a,b, 2006, 2007). Posteriormente, em outros trabalhos, estas espécies fitorremediaram o herbicida tebuthiuron em menores niveis (Pires et al., 2005a,b, 2006), devido à persistência do produto no solo (Meyer \& Bovey, 1988; Johnsen \& Morton, 1991). Recentemente, o picloram tem sido estudado com enfoque remediador, por suas características de mobilidade e persistência no solo e pela crescente difusão da integração lavoura-pecuária. Resíduos no solo do picloram podem resultar em sintomas de intoxicação à soja e feijão, cultivados em sucessão, após a renovação da pastagem. Ferreira et al. (2006) e Silva et al. (2006) evidenciaram que Brachiaria brizantha, $B$. decumbens e Avena strigosa não foram afetadas pela presença do picloram no solo.

A seleção de espécies vegetais para remediação de compostos herbicidas tem limitações mais complexas, comparativamente a programas que visam a descontaminação de metais pesados, pois herbicidas são contaminantes que apresentam diversidade molecular e maior complexidade de análise, diante das constantes transformações a que estão sujeitos (Pires et al., 2003b). Além disso, o contaminante no caso, o herbicida - é desenvolvido como agente para controle do descontaminante - no 
caso, as plantas (Santos et al., 2006). Por isso, a seleção de plantas para remediação de herbicidas exige, normalmente, que seja avaliado inicialmente um número elevado de espécies, como verificado nos trabalhos desenvolvidos por Procópio et al. (2004a,b) e Santos et al. (2004b), para seletividade ao trifloxysulfuronsodium, e por Pires et al. (2003a,c), selecionando plantas para remediação de tebuthiuron.

O objetivo deste trabalho foi selecionar espécies que apresentem tolerância à presença do herbicida picloram no solo, para posterior utilização em programas de fitorremediação de solos contaminados com este herbicida.

\section{MATERIAL E MÉTODOS}

O experimento foi realizado no período de outubro a dezembro de 2005, em casa de vegetação localizada no campus da Fesurv - Universidade de Rio Verde, em Rio Verde-GO.

Os tratamentos foram compostos pela combinação entre 19 espécies vegetais [Brachiaria brizantha (cv. Marandu); Brachiaria brizantha (cv. MG-5 Vitória); Brachiaria brizantha (cv. Mulato); Brachiaria decumbens; Brachiaria humidicola; Brachiaria ruziziensis; Panicum maximum (cv. Massai); Panicum maximum (cv. Mombaça); Panicum maximum (cv. Tanzânia); Pennisetum purpureum $\mathrm{x}$ Pennisetum glaucumcapim-elefante (cv. Paraíso); Eleusine coracana - capim-pé-de-galinha-gigante; Pennisetum glaucum - milheto (cv. ADR-300); Pennisetum glaucum - milheto (cv. ADR-500); Sorghum bicolor $x$ Sorghum sudanense - Cover Crop; Sorghum bicolor $x$ Sorghum sudanense - sorgo (cv. Jumbo); Paspalum atratum - capim-pojuca; Zea mays - milho (híbrido Coodetec 208); Canavalia ensiformis - feijão-de-porco; e Stizolobium aterrimum - mucuna-preta] e de cinco doses do picloram $(0,80,160,320$ e $640 \mathrm{~g} \mathrm{ha}^{-1}$ ), totalizando 95 tratamentos. O delineamento experimental utilizado foi o de blocos casualizados em esquema fatorial $19 \times 5$, com quatro repetições.

Como substrato para o crescimento das plantas, utilizaram-se amostras de solo classificado como Latossolo Vermelho eutroférrico, cuja análise química e física se encontra na Tabela 1. Antes do preenchimento dos vasos com fundo fechado e capacidade para $8 \mathrm{dm}^{3}$, foi realizada calagem, utilizando-se o equivalente a $2 \mathrm{t} \mathrm{ha}^{-1}$ de calcário filler, e adubação de base, aplicando-se o equivalente a $500 \mathrm{~kg} \mathrm{ha}^{-1}$ da fórmula 08-20-18.

Após o preenchimento e umedecimento dos vasos, procedeu-se à aplicação do herbicida picloram, utilizando-se um pulverizador costal pressurizado com $\mathrm{CO}_{2}$, acoplado de barra contendo duas pontas de pulverização TT 110.02, aplicando volume de calda equivalente a $200 \mathrm{~L} \mathrm{ha}^{-1}$.

Após 15 dias da aplicação do herbicida, foi realizada a semeadura das espécies vegetais,

Tabela 1 - Composição físico-química $(0-20 \mathrm{~cm})$ do solo utilizado no experimento

\begin{tabular}{|c|c|c|c|c|c|c|c|c|}
\hline \multicolumn{9}{|c|}{ Análise química } \\
\hline M.O. & $\mathrm{Ca}+\mathrm{Mg}$ & $\mathrm{Ca}$ & $\mathrm{K}$ & $\mathrm{Mg}$ & $\mathrm{Al}$ & $\mathrm{H}+\mathrm{Al}$ & $\mathrm{K}$ & P (Mellich) \\
\hline $\mathrm{g} \mathrm{kg}^{-1}$ & \multicolumn{6}{|c|}{ - } & \multicolumn{2}{|c|}{----------- $\mathrm{mg} \mathrm{dm}^{-3}$} \\
\hline 12,79 & 0,27 & 0,06 & 0,04 & 0,21 & 0,05 & 2,9 & 17 & 0,30 \\
\hline \multicolumn{6}{|c|}{ Dado complementar } & \multicolumn{3}{|c|}{ Análise granulométrica } \\
\hline $\mathrm{pH}$ & $\mathrm{m}$ & $\mathrm{V}$ & \multicolumn{2}{|c|}{ CTC } & SB & \multicolumn{3}{|c|}{ Textura $(\%)$} \\
\hline $\mathrm{CaCl}_{2} 0,01 \mathrm{M}$ & $\%$ & $\%$ & \multicolumn{3}{|c|}{$\mathrm{cmol}_{\mathrm{c}} \mathrm{dm}^{-3}$} & Argila & Silte & Areia \\
\hline 4,09 & 13,65 & 9,88 & 3 , & & 0,32 & 56 & 15 & 29 \\
\hline
\end{tabular}

*Análises realizadas nos Laboratórios de Análises Físicas e Químicas de Solo da Faculdade de Agronomia da Fesurv - Universidade de Rio Verde, segundo a metodologia descrita pela Empresa Brasileira de Pesquisa Agropecuária-Embrapa (1997). 
utilizando-se número de sementes por vaso equivalente à recomendação comercial de cada forrageira. Todos os vasos foram irrigados duas vezes ao dia, para manutenção da umidade do solo.

Aos 34 e 84 dias após a aplicação dos tratamentos herbicidas, avaliou-se a fitotoxicidade de forma visual, utilizando-se escala percentual, em que $0 \%$ significa a ausência de sintomas e $100 \%$ a morte de todas as plantas.

Após coleta e tabulação dos dados, estes foram submetidos à análise de variância. A análise dos efeitos significativos das espécies vegetais dentro de cada dose do herbicida foi realizada por meio do critério de agrupamento de médias de Scott Knott a 5\% de significância, e os efeitos significativos das doses do picloram em cada espécie, por análise de re- gressão, sendo os coeficientes das equações testados pelo teste $\mathrm{t}$ a $5 \%$ de significância.

\section{RESULTADOS E DISCUSSÃO}

As espécies vegetais avaliadas diferiram quanto à tolerância ao herbicida picloram presente no solo. Com a aplicação da menor dose de picloram (80 $\left.\mathrm{g} \mathrm{ha}^{-1}\right)$, a espécie que se mostrou mais suscetivel, na avaliação realizada aos 34 dias após a aplicação (DAA), foi a mucuna-preta, que apresentou fitotoxicidade média decorrente dos efeitos desse herbicida de 86,8\% (Tabela 2). Excetuando-se a alta sensibilidade exibida pelas plantas de mucuna-preta, as espécies/cultivares feijão-de-porco, capim-pojuca, Marandu, capim-elefante e Massai apresentaram os maiores niveis de intoxicação, aos 34 DAA, quando cultivadas em

Tabela 2 - Fitotoxicidade de espécies vegetais cultivadas em solo contaminado com diferentes níveis do herbicida picloram, 34 dias após aplicação do herbicida. Rio Verde, 2006

\begin{tabular}{|c|c|c|c|c|c|c|}
\hline \multirow{3}{*}{ Espécie vegetal } & \multicolumn{5}{|c|}{ Dose de picloram $\left(\mathrm{g} \mathrm{ha}^{-1}\right)$} & \multirow{2}{*}{ Média } \\
\hline & 0 & 80 & 160 & 320 & 640 & \\
\hline & \multicolumn{6}{|c|}{ Fitotoxicidade (\%) } \\
\hline 1. Brachiaria brizantha (cv. Marandu) & $0,0 \mathrm{a}$ & $22,7 \mathrm{~b}$ & $88,0 \mathrm{a}$ & $90,0 \mathrm{a}$ & $90,0 \mathrm{a}$ & 58,1 \\
\hline 2. Brachiaria brizantha (cv. MG-5 Vitória) & $0,0 \mathrm{a}$ & $5,0 \mathrm{c}$ & $35,0 \mathrm{c}$ & $37,0 \mathrm{c}$ & $92,0 \mathrm{a}$ & 33,8 \\
\hline 3. Brachiaria brizantha (cv. Mulato) & $0,0 \mathrm{a}$ & $7,3 \mathrm{c}$ & $66,3 \mathrm{~b}$ & $65,7 \mathrm{~b}$ & $86,5 \mathrm{a}$ & 45,1 \\
\hline 4. Brachiaria decumbens & $0,0 \mathrm{a}$ & $8,0 \mathrm{c}$ & $29,5 \mathrm{c}$ & $41,7 \mathrm{c}$ & $91,0 \mathrm{a}$ & 34,0 \\
\hline 5. Brachiaria humidicola & $0,0 \mathrm{a}$ & $16,3 \mathrm{c}$ & $34,3 \mathrm{c}$ & $53,7 \mathrm{~b}$ & $97,5 \mathrm{a}$ & 40,4 \\
\hline 6. Brachiaria ruziziensis & $0,0 \mathrm{a}$ & $6,3 \mathrm{c}$ & $34,0 \mathrm{c}$ & $52,5 \mathrm{c}$ & $91,5 \mathrm{a}$ & 36,9 \\
\hline 7. Panicum maximum (cv. Massai) & $0,0 \mathrm{a}$ & $19,0 \mathrm{~b}$ & $40,3 \mathrm{c}$ & $67,0 \mathrm{~b}$ & $90,0 \mathrm{a}$ & 43,3 \\
\hline 8. Panicum maximum (cv. Mombaça) & $0,0 \mathrm{a}$ & $1,0 \mathrm{~d}$ & $37,3 \mathrm{c}$ & $50,0 \mathrm{c}$ & $91,3 \mathrm{a}$ & 35,9 \\
\hline 9. Panicum maximum (cv. Tanzânia) & $0,0 \mathrm{a}$ & $0,0 \mathrm{~d}$ & $31,0 \mathrm{c}$ & $67,8 \mathrm{~b}$ & $81,8 \mathrm{a}$ & 36,1 \\
\hline $\begin{array}{l}\text { 10. Pennisetum purpureum } \times \text { Pennisetum glaucum- } \\
\text { capim-elefante (cv. Paraíso) }\end{array}$ & $0,0 \mathrm{a}$ & $19,7 \mathrm{~b}$ & $27,7 \mathrm{c}$ & $93,7 \mathrm{a}$ & $98,8 \mathrm{a}$ & 48,0 \\
\hline 11. Eleusine coracana - capim-pé-de-galinha-gigante & $0,0 \mathrm{a}$ & $1,3 \mathrm{~d}$ & $2,5 \mathrm{e}$ & $19,0 \mathrm{~d}$ & $25,6 \mathrm{~b}$ & 9,7 \\
\hline 12. Pennisetum glaucum - milheto (cv. ADR-300) & $0,0 \mathrm{a}$ & $7,3 \mathrm{c}$ & $7,3 \mathrm{~d}$ & $9,0 \mathrm{e}$ & $10,1 \mathrm{c}$ & 6,8 \\
\hline 13. Pennisetum glaucum - milheto (cv. ADR-500) & $0,0 \mathrm{a}$ & $10,0 \mathrm{c}$ & $11,3 \mathrm{~d}$ & $11,0 \mathrm{e}$ & $28,7 \mathrm{~b}$ & 12,2 \\
\hline 14. Sorghum bicolor $x$ Sorghum sudanense-Cover Crop & $0,0 \mathrm{a}$ & $1,0 \mathrm{~d}$ & $9,0 \mathrm{~d}$ & $29,0 \mathrm{~d}$ & $65,0 \mathrm{a}$ & 20,8 \\
\hline $\begin{array}{l}\text { 15. Sorghum bicolor } x \text { Sorghum sudanense-sorgo (cv. } \\
\text { Jumbo) }\end{array}$ & $0,0 \mathrm{a}$ & $4,0 \mathrm{c}$ & $9,3 \mathrm{~d}$ & $19,3 \mathrm{~d}$ & $34,5 \mathrm{~b}$ & 13,4 \\
\hline 16. Paspalum atratum - capim-pojuca & $0,0 \mathrm{a}$ & $26,5 \mathrm{~b}$ & $41,0 \mathrm{c}$ & $56,5 \mathrm{~b}$ & $97,0 \mathrm{a}$ & 44,2 \\
\hline 17. Zea mays - milho (híbrido Coodetec 208) & $0,0 \mathrm{a}$ & $1,8 \mathrm{~d}$ & $2,5 \mathrm{e}$ & $3,0 \mathrm{f}$ & $5,0 \mathrm{c}$ & 2,5 \\
\hline 18. Canavalia ensiformis - feijão-de-porco & $0,0 \mathrm{a}$ & $27,7 \mathrm{~b}$ & $85,5 \mathrm{a}$ & $97,0 \mathrm{a}$ & $99,5 \mathrm{a}$ & 61,9 \\
\hline 19. Stizolobium aterrimum - mucuna-preta & $0,0 \mathrm{a}$ & $86,8 \mathrm{a}$ & $98,5 \mathrm{a}$ & $100,0 \mathrm{a}$ & $100,0 \mathrm{a}$ & 77,1 \\
\hline Média & 0,0 & 14,3 & 36,3 & 50,7 & 72,4 & 34,7 \\
\hline
\end{tabular}

Médias seguidas pelas mesmas letras na coluna não diferem estatisticamente entre si pelo teste de Scott Knott a 5\% de probabilidade. 
solo que recebeu aplicação de $80 \mathrm{~g}^{\text {ha }}{ }^{-1}$ de picloram; contudo, tais niveis não atingiram 30\%, sendo considerados aceitáveis do ponto de vista agronômico. Ainda, analisando os efeitos do picloram nessa avaliação inicial e nesse mesmo nivel de contaminação no solo, constatouse que as espécies/cultivares Tanzânia, Mombaça, Cover Crop, capim-pé-de-galinhagigante e milho se mostraram extremamente tolerantes (Tabela 2), com sintomatologia quase imperceptivel. Freitas et al. (2003) não detectaram efeitos fitotóxicos sobre gramabatatais (Paspalum notatum) 20 dias após a aplicação da mistura comercial de 2,4-D + picloram na dose de $480+128 \mathrm{~g} \mathrm{ha}^{-1}$.

As leguminosas mucuna-preta e feijão-deporco e o cultivar forrageiro Marandu foram as plantas mais sensiveis quando semeadas em solo que recebeu $160 \mathrm{~g} \mathrm{ha}^{-1}$ de picloram, na avaliação realizada aos 34 DAA, apresentando níveis de injúrias superiores a $85 \%$ (Tabela 2). O cultivar Mulato, da espécie Brachiaria brizantha, apresentou menor sensibilidade que as espécies anteriores, porém ainda em nivel elevado $(66,3 \%$ de fitotoxicidade). Os maiores níveis de tolerância ao cultivo em solos que receberam $160 \mathrm{~g}^{-1} \mathrm{~h}^{-1}$ de picloram foram observados nas espécies capim-pé-degalinha-gigante e milho; todavia, os cultivares ADR-300, Cover Crop, Jumbo e ADR-500 também mostraram tolerância satisfatória. Butler et al. (2006) não observaram injúrias em plantas de Cynodon dactylon após aplicação prévia da mistura pré-formulada do herbicida picloram com 2,4-D.

Quando se aplicaram $320 \mathrm{~g} \mathrm{ha}^{-1}$ de picloram ao solo antes da semeadura das espécies, foram constatados sintomas de intoxicação muito elevados, aos 34 DAA, nas espécies/cultivares mucuna-preta (morte de todas as plantas), feijão-de-porco, capim-elefante e Marandu (Tabela 2). Ainda, nessa avaliação e nesse nível de contaminação, fitotoxicidade expressiva foi verificada nas plantas de Tanzânia, Massai, Mulato, capim-pojuca e Brachiaria humidicola. O milho foi a espécie mais tolerante a esse nivel de herbicida no solo, seguido dos dois cultivares de milheto ADR-300 e ADR-500.

Avaliando a tolerância dos três cultivares de $B$. brizantha (Marandu, MG-5 Vitória e Mulato) ao cultivo em solos contaminados com o picloram, observou-se que na primeira avaliação (34 DAA) o cultivar Marandu foi o mais sensivel, quando submetido aos niveis de 80,160 e $320 \mathrm{~g} \mathrm{ha}^{-1}$ do herbicida, e o cultivar MG-5 Vitória, o mais tolerante (Tabela 2). Esses resultados demonstram sensibilidade diferencial intra-específica, não sendo correto o emprego de generalizações, quanto à seletividade de herbicidas a essa espécie, sem antes terem sido realizadas investigações em nivel varietal.

As plantas de milho e do cultivar de milheto ADR-300 mostraram-se eficientes em tolerar inicialmente altos niveis de picloram no solo, sendo os valores médios de fitotoxicidade para essas espécies de 5,0 e $10,1 \%$, respectivamente, na avaliação realizada aos 34 DAA, para a dose de $640 \mathrm{~g} \mathrm{ha}^{-1}$, equivalente a duas vezes mais a quantidade de picloram presente na dose comercial do herbicida Tordon ${ }^{\circledR}$. Tolerância inicial aceitável, para esse nivel de contaminação, também foi verificada para as espécies/cultivares capim-pé-de-galinhagigante, ADR-500 e Jumbo. Nessas mesmas condições, as demais espécies exibiram sintomas de injúria bastante acentuados, superiores a $80 \%$.

Não foram detectados sintomas de fitotoxicidade, aos $84 \mathrm{DAE}$, nas espécies/cultivares MG-5 Vitória, capim-pé-de-galinha-gigante e Cover Crop cultivadas em solo que recebeu $80 \mathrm{~g} \mathrm{ha}^{-1}$ de picloram, que não diferiram do observado nas plantas de $B$. humidicola $(1,0 \%)$ (Tabela 3). Nessa avaliação, ainda foram verificados baixos niveis de injúrias nas espécies/ cultivares milho $(2,0 \%), B$. decumbens $(3,3 \%)$, B. ruziziensis $(4,7 \%)$, ADR-300 (6,0\%) e ADR$500(6,0 \%)$; apenas nas plantas de mucunapreta a ação do herbicida foi muito intensa, chegando a provocar fitotoxicidade média de 90,3\%. Sabe-se que o picloram é um herbicida utilizado principalmente no controle de dicotiledôneas infestantes de pastagens (Cheng, 1969); contudo, ressalta-se a discrepância entre as respostas mostradas pelas duas únicas dicotiledôneas avaliadas no ensaio - mucunapreta e feijão-de-porco - quando submetidas ao menor nível de picloram no solo $\left(80 \mathrm{~g} \mathrm{ha}^{-1}\right)$. As plantas de feijão-de-porco se apresentaram mais tolerantes à atividade do picloram no solo, em relação à mucuna-preta; a fitotoxicidade verificada nas plantas de mucuna-preta, aos 34 DAA, foi aproximadamente três vezes 
Tabela 3 - Fitotoxicidade de espécies vegetais cultivadas em solo contaminado com diferentes níveis do herbicida picloram, 84 dias após aplicação do herbicida. Rio Verde, 2006

\begin{tabular}{|c|c|c|c|c|c|c|}
\hline \multirow{3}{*}{ Espécie vegetal } & \multicolumn{5}{|c|}{ Doses de picloram $\left(\mathrm{g} \mathrm{ha}^{-1}\right)$} & \multirow{2}{*}{ Média } \\
\hline & 0 & 80 & 160 & 320 & 640 & \\
\hline & \multicolumn{6}{|c|}{ Fitotoxicidade (\%) } \\
\hline 1. Brachiaria brizantha (cv. Marandu) & $0,0 \mathrm{a}$ & $15,7 \mathrm{~d}$ & $63,0 \mathrm{~b}$ & $81,8 \mathrm{a}$ & $89,5 \mathrm{a}$ & 50,0 \\
\hline 2. Brachiaria brizantha (cv. MG-5 Vitória) & $0,0 \mathrm{a}$ & $0,0 \mathrm{f}$ & $21,0 \mathrm{~d}$ & $34,5 \mathrm{c}$ & $69,3 \mathrm{~b}$ & 25,0 \\
\hline 3. Brachiaria brizantha (cv. Mulato) & $0,0 \mathrm{a}$ & $10,7 \mathrm{~d}$ & $28,3 \mathrm{~d}$ & $48,0 \mathrm{c}$ & $67,3 \mathrm{~b}$ & 30,9 \\
\hline 4. Brachiaria decumbens & $0,0 \mathrm{a}$ & $3,3 \mathrm{e}$ & $20,0 \mathrm{~d}$ & $45,7 \mathrm{c}$ & $67,8 \mathrm{~b}$ & 27,3 \\
\hline 5. Brachiaria humidicola & $0,0 \mathrm{a}$ & $1,0 \mathrm{f}$ & $24,3 \mathrm{~d}$ & $39,3 \mathrm{c}$ & $97,8 \mathrm{a}$ & 32,5 \\
\hline 6. Brachiaria ruziziensis & $0,0 \mathrm{a}$ & $4,7 \mathrm{e}$ & $23,0 \mathrm{~d}$ & $41,3 \mathrm{c}$ & $85,5 \mathrm{a}$ & 30,9 \\
\hline 7. Panicum maximum (cv. Massai) & $0,0 \mathrm{a}$ & $8,5 \mathrm{~d}$ & $32,0 \mathrm{c}$ & $63,8 \mathrm{~b}$ & $87,0 \mathrm{a}$ & 38,3 \\
\hline 8. Panicum maximum (cv. Mombaça) & $0,0 \mathrm{a}$ & $11,7 \mathrm{~d}$ & $36,3 \mathrm{c}$ & $50,3 \mathrm{c}$ & $88,3 \mathrm{a}$ & 37,3 \\
\hline 9. Panicum maximum (cv. Tanzânia) & $0,0 \mathrm{a}$ & $7,7 \mathrm{~d}$ & $25,3 \mathrm{~d}$ & $60,3 \mathrm{~b}$ & $80,5 \mathrm{a}$ & 34,8 \\
\hline $\begin{array}{l}\text { 10. Pennisetum purpureum } \mathrm{x} \text { Pennisetum glaucum- } \\
\text { capim-elefante (cv. Paraíso) }\end{array}$ & $0,0 \mathrm{a}$ & $20,0 \mathrm{c}$ & $22,0 \mathrm{~d}$ & $91,0 \mathrm{a}$ & 99,3 a & 46,5 \\
\hline 11. Eleusine coracana - capim-pé-de-galinha-gigante & $0,0 \mathrm{a}$ & $0,0 \mathrm{f}$ & $19,0 \mathrm{~d}$ & $44,3 \mathrm{c}$ & $47,7 \mathrm{c}$ & 22,2 \\
\hline 12. Pennisetum glaucum - milheto (cv. ADR-300) & $0,0 \mathrm{a}$ & $6,0 \mathrm{e}$ & $30,3 \mathrm{c}$ & $48,5 \mathrm{c}$ & $53,3 \mathrm{c}$ & 27,6 \\
\hline 13. Pennisetum glaucum - milheto (cv. ADR-500) & $0,0 \mathrm{a}$ & $6,0 \mathrm{e}$ & $23,7 \mathrm{~d}$ & $42,5 \mathrm{c}$ & $45,0 \mathrm{c}$ & 23,4 \\
\hline 14. Sorghum bicolor $x$ Sorghum sudanense- Cover Crop & $0,0 \mathrm{a}$ & $0,0 \mathrm{f}$ & $9,5 \mathrm{e}$ & $26,3 \mathrm{~d}$ & $55,5 \mathrm{c}$ & 18,3 \\
\hline $\begin{array}{l}\text { 15. Sorghum bicolor } x \text { Sorghum sudanense- sorgo (cv. } \\
\text { Jumbo) }\end{array}$ & $0,0 \mathrm{a}$ & $19,3 \mathrm{c}$ & $35,3 \mathrm{c}$ & $36,3 \mathrm{c}$ & $65,0 \mathrm{~b}$ & 31,2 \\
\hline 16. Paspalum atratum-capim-pojuca & $0,0 \mathrm{a}$ & $11,0 \mathrm{~d}$ & $39,5 \mathrm{c}$ & $78,0 \mathrm{a}$ & $97,0 \mathrm{a}$ & 45,1 \\
\hline 17. Zea mays - milho (híbrido Coodetec 208) & $0,0 \mathrm{a}$ & $2,0 \mathrm{e}$ & $8,7 \mathrm{e}$ & $19,3 \mathrm{~d}$ & $22,0 \mathrm{~d}$ & 10,4 \\
\hline 18. Canavalia ensiformis - feijão-de-porco & $0,0 \mathrm{a}$ & $39,3 \mathrm{~b}$ & $95,3 \mathrm{a}$ & $100,0 \mathrm{a}$ & $100,0 \mathrm{a}$ & 66,9 \\
\hline 19. Stizolobium aterrimum - mucuna-preta & $0,0 \mathrm{a}$ & $90,3 \mathrm{a}$ & $100,0 \mathrm{a}$ & $100,0 \mathrm{a}$ & $100,0 \mathrm{a}$ & 78,1 \\
\hline Média & 0,0 & 13,5 & 34,6 & 55,3 & 74,6 & 35,6 \\
\hline
\end{tabular}

Médias seguidas pelas mesmas letras na coluna não diferem estatisticamente entre si pelo teste de Scott Knott a 5\% de probabilidade.

maior do que a observada nas plantas de feijãode-porco, e aos 84 DAA, maior que o dobro. No entanto, esse comportamento se restringiu apenas ao menor nível de contaminação, pois nas doses de 160, 320 e $640 \mathrm{~g} \mathrm{ha}^{-1}$ não se observaram diferenças quanto à suscetibilidade dessas espécies, e estas não suportaram tais níveis do picloram no solo de cultivo, sendo, praticamente, controladas totalmente. Silva \& Bueno (2000) verificaram que Stizolobium aterrimum - mucuna-preta foi tolerante aos herbicidas alachlor, imazaquin e pendimethalin, sendo suscetivel apenas ao 2,4-DB.

Maior tolerância ao cultivo em solos contaminados com $160 \mathrm{~g} \mathrm{ha}^{-1}$ do herbicida foi constatada, aos 84 DAA, nas espécies/cultivares milho e Cover Crop, onde se observaram valores de intoxicação inferiores a 10\% (Tabela 3). As maiores injúrias, nessa avaliação, foram veri- ficadas nas espécies mucuna-preta e feijãode-porco, porém as plantas do cultivar Marandu também foram severamente danificadas pelo residual do picloram no solo. Ressalta-se que as demais espécies/cultivares avaliadas apresentaram fitotoxicidade média, variando de 19,0\% (capim-pé-de-galinha-gigante) a 39,5\% (capim-pojuca) (Tabela 3).

$\mathrm{Na}$ primeira avaliação, realizada aos 34 DAA, o cultivar Massai foi, dentre os cultivares de Panicum maximum avaliados, o que mostrou maior suscetibilidade à ação do picloram no solo, somente quando aplicado nas doses de 80 e $320 \mathrm{~g} \mathrm{ha}^{-1}$, não diferindo do cultivar Tanzânia. Na avaliação final, Tanzânia foi o cultivar de $P$. maximum mais tolerante no nivel de contaminação de $160 \mathrm{~g} \mathrm{ha}^{-1}$ e Mombaça, o mais no nivel de $320 \mathrm{~g} \mathrm{ha}^{-1}$ (Tabela 3). Ressalta-se que, mesmo havendo tais diferenças, 
nenhum dos cultivares de $P$. maximum apresentou tolerância satisfatória quando cultivados em solos que receberam 320 e $640 \mathrm{~g} \mathrm{ha}^{-1}$ de picloram.

Novamente, milho e Cover Crop suportaram mais eficientemente a presença do picloram no solo $\left(320 \mathrm{~g} \mathrm{ha}^{-1}\right)$, sendo esses efeitos avaliados aos 84 DAA (Tabela 3). Nessa avaliação, constatou-se que mucuna-preta, feijãode-porco, capim-elefante, Marandu e capimpojuca foram as espécies/cultivares mais suscetiveis à ação fitotóxica do picloram, apresentando intoxicação média variando de 78,0 a 100,0\%. Também devem ser destacados os niveis de fitotoxicidade elevados observados nas plantas de Massai $(63,8 \%)$ e Tanzânia $(60,3 \%)$.

Os cultivares de milheto avaliados (ADR300 e ADR-500) mostraram niveis de tolerância ao herbicida picloram bastante semelhantes na última avaliação (84 DAA); apenas na aplicação da dose de $320 \mathrm{~g} \mathrm{ha}^{-1}$ do herbicida é que se verificou um pouco mais de sintomas nas plantas do cultivar ADR-300. Dowler \& Wright (1995) verificaram baixa tolerância do milheto aos herbicidas atrazine, propachlor e pendimethalin, utilizados isoladamente e em misturas.

Com exceção das plantas de milho, todas as demais espécies avaliadas apresentaram níveis de fitotoxicidade maiores que $40 \%$ quando cultivadas em solo onde se aplicaram $640 \mathrm{~g}$ ha ${ }^{1}$ de picloram, aos 84 DAA (Tabela 3). No entanto, as espécies/cultivares mucunapreta, feijão-de-porco, capim-elefante, $B$. humidicola, capim-pojuca, Marandu, Mombaça, Massai e Tanzânia foram as mais afetadas pela ação tóxica do herbicida.

O aumento dos niveis de contaminação do solo com a aplicação do herbicida picloram ocasionou incrementos diferenciados na fitotoxicidade das espécies vegetais avaliadas, conforme demonstrado nas Figuras de 1 a 4 .

Todas as plantas do gênero Brachiaria avaliadas apresentaram ligeira recuperação dos sintomas iniciais de fitotoxicidade, avaliados aos 34 DAA, porém em niveis pouco significativos, com maior destaque para a recuperação demonstrada pelas plantas de Mulato, MG-5 Vitória e B. decumbens (Figura 1). Em relação ao cultivar Marandu, a fitotoxicidade média final com a aplicação da dose de
$640 \mathrm{~g} \mathrm{ha}^{-1}$ do herbicida ficou próxima de $90 \%$. Somente na dose de $87,6 \mathrm{~g}_{\text {ha }}^{-1}$ é que os patamares de intoxicação vistos podem ser considerados aceitáveis (máximo de $35 \%$ ) para esse cultivar, diferentemente do cultivar MG-5 Vitória, em que a convivência das plantas desse cultivar pode se dar em niveis aceitáveis até a aplicação da dose de 324,2 $\mathrm{g}_{\text {ha }}{ }^{-1}$ de picloram. O cultivar Mulato apresentou como dose-limite de picloram no solo 220,3 $\mathrm{g} \mathrm{ha}^{-1}$, valor este intermediário em relação aos outros cultivares de B.brizantha avaliados (Marandu e MG-5 Vitória). O nível máximo aceitável de picloram no solo para as plantas das espécies $B$. decumbens, $B$. humidicola e $B$. ruziziensis foi de 274,$7 ; 240,8$; e $264,5 \mathrm{~g}^{\text {ha }}{ }^{-1}$, respectivamente.

Os cultivares de $P$. maximum não apresentaram recuperação ou mesmo agravamento dos sintomas de fitotoxicidade promovidos pela absorção do herbicida picloram presente no solo de plantio (Figura 2). Quando esses cultivares foram cultivados em solo que recebeu aplicação de $640 \mathrm{~g}^{\text {ha-1 }}{ }^{-1}$ do herbicida, os valores finais de intoxicação das plantas situaram-se entre 80 e 90\%. No entanto, nas doses de 173,$2 ; 190,7$; e 198, $1 \mathrm{~g} \mathrm{ha}^{-1}$ do picloram é que se encontraram os níveis aceitáveis de injúrias, respectivamente para os cultivares Massai, Mombaça e Tanzânia. Segundo Bovey \& Scifres (1971), concentrações de picloram de $100 \mathrm{mg} \mathrm{m}^{-3} \mathrm{em}$ solos podem causar significante redução no crescimento de plantas de Panicum virgatum.

O capim-elefante não tolerou a semeadura em solo onde foram aplicados $640 \mathrm{~g}^{\text {ha }}{ }^{-1}$ de picloram, ocorrendo, praticamente, a morte das plantas já na fase inicial de seu desenvolvimento (Figura 2). A aplicação de 132,4 $\mathrm{g} \mathrm{ha}^{-1}$ de picloram foi a dose máxima aplicada ao solo para que a fitotoxicidade às plantas de capimelefante não ultrapassasse os níveis aceitáveis.

Os sintomas de fitotoxicidade verificados nas plantas do capim-pé-de-galinha-gigante, devido ao seu cultivo em solo contaminado com o herbicida picloram, aumentaram com o passar do tempo, ficando, porém, abaixo de $50 \%$ quando se aplicou a maior dose do herbicida (640 $\mathrm{g} \mathrm{ha}^{1}$ ) (Figura 2). Diante disso, o nível de intoxicação aceitável das plantas dessa espécie ocorreu na dose de 332,6 $\mathrm{g} \mathrm{ha}^{-1}$ de picloram. 
Brachiaria brizantha (cv. Marandu)

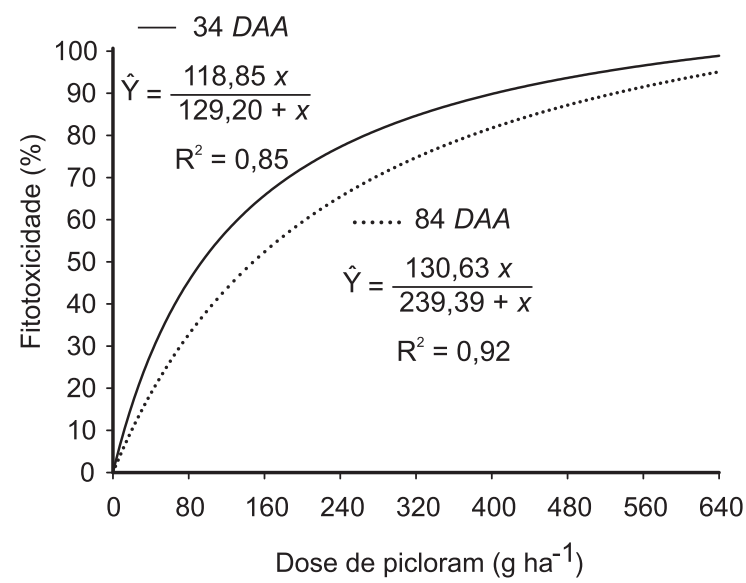

Brachiaria brizantha (cv. Mulato)

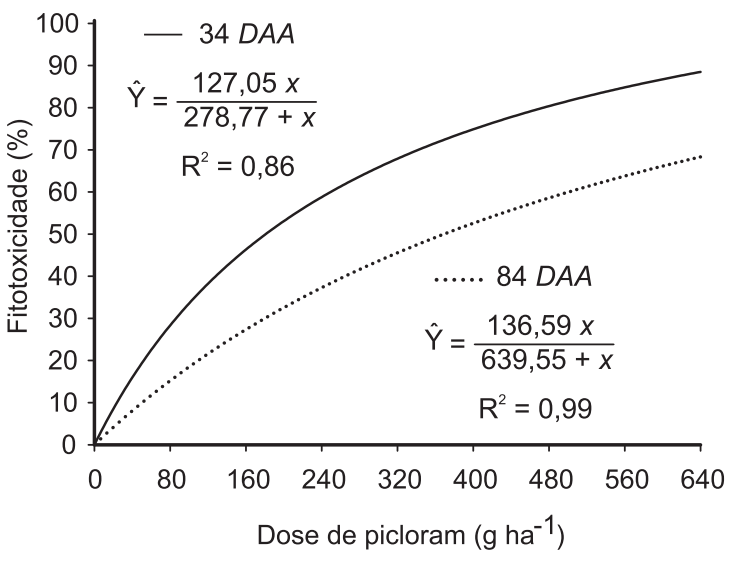

Brachiaria humidicola

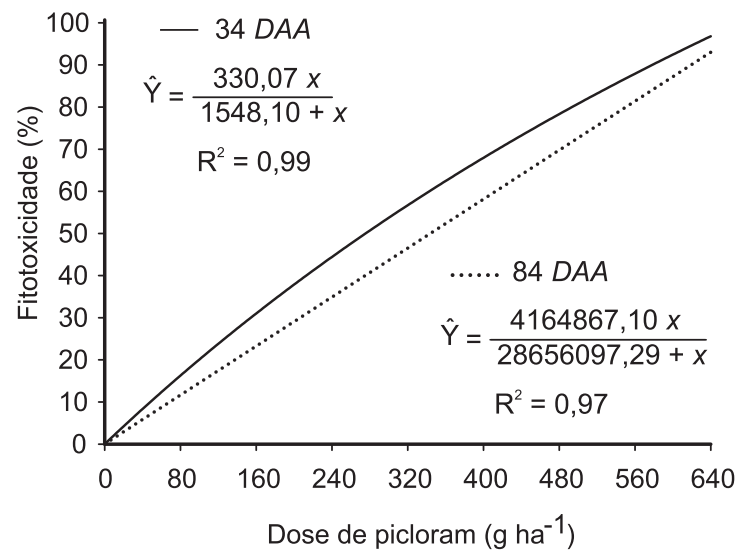

Brachiaria brizantha (cv. Marandu)

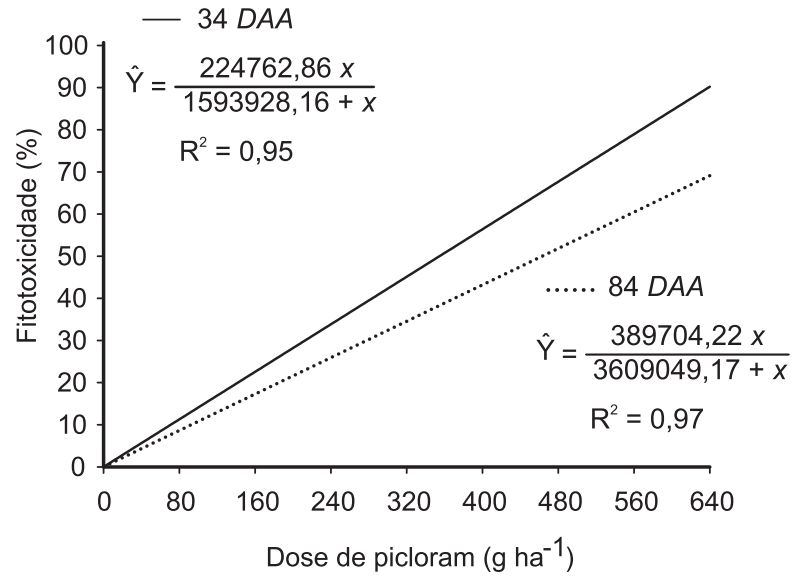

Brachiaria decumbens

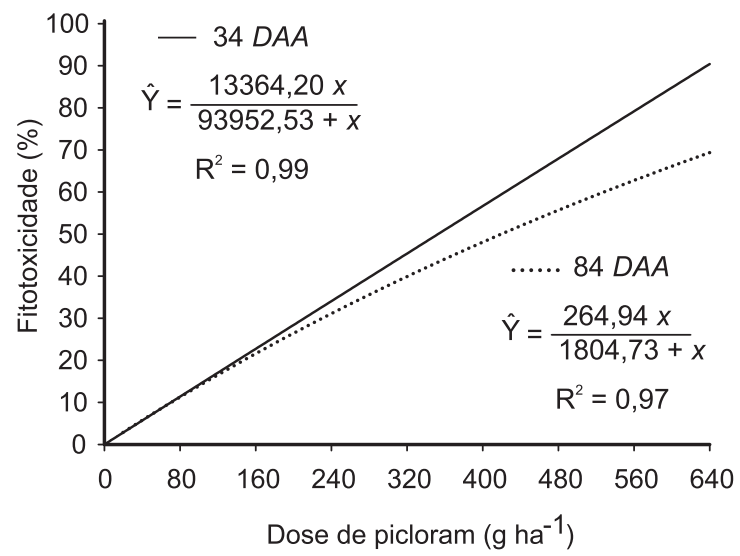

Brachiaria ruziziensis

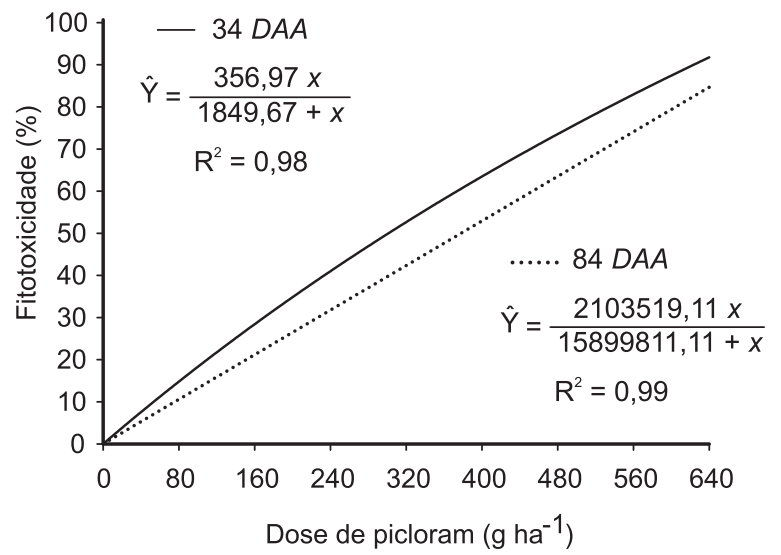

Figura 1 - Fitotoxicidade em plantas cultivadas em solo contaminado com diferentes níveis do herbicida picloram. Rio Verde, 2006. 


\section{Panicum maximum (cv. Massai)}

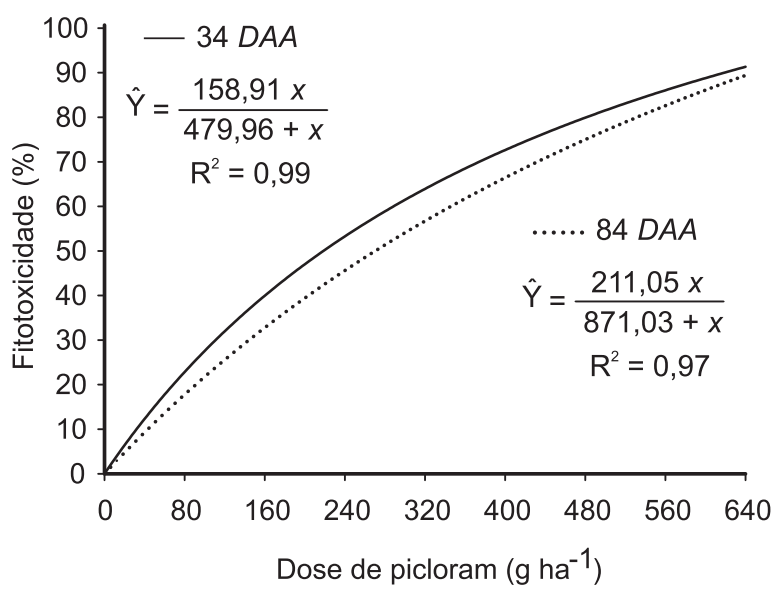

Panicum maximum (cv. Tanzânia)

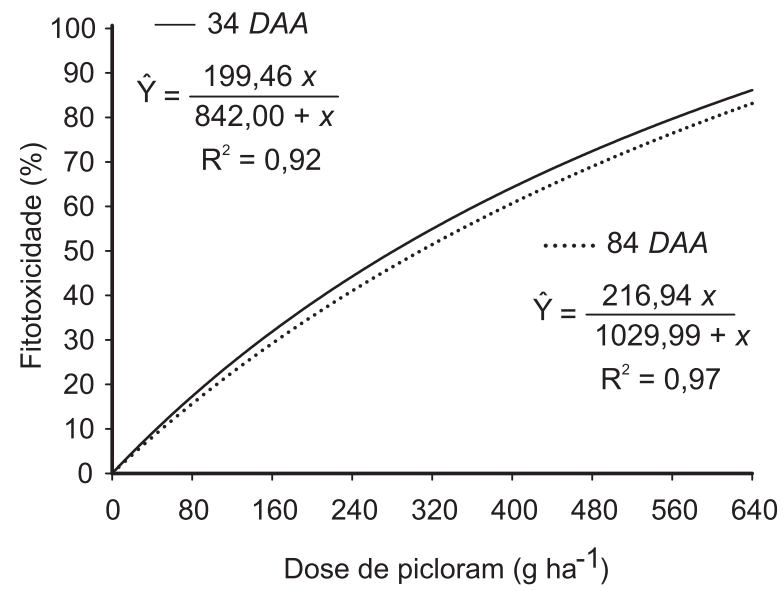

Eleusine coracana - capim-pé-de-galinha-gigante

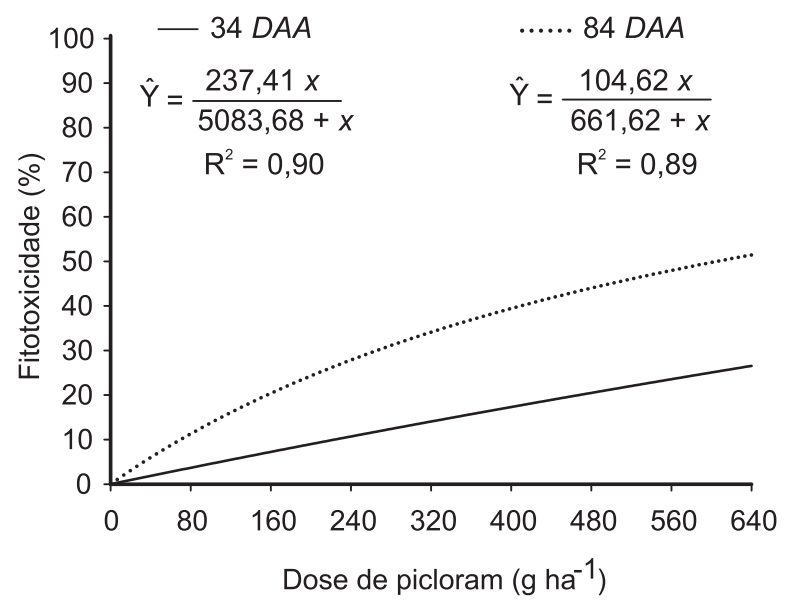

Panicum maximum (cv. Mombaça)

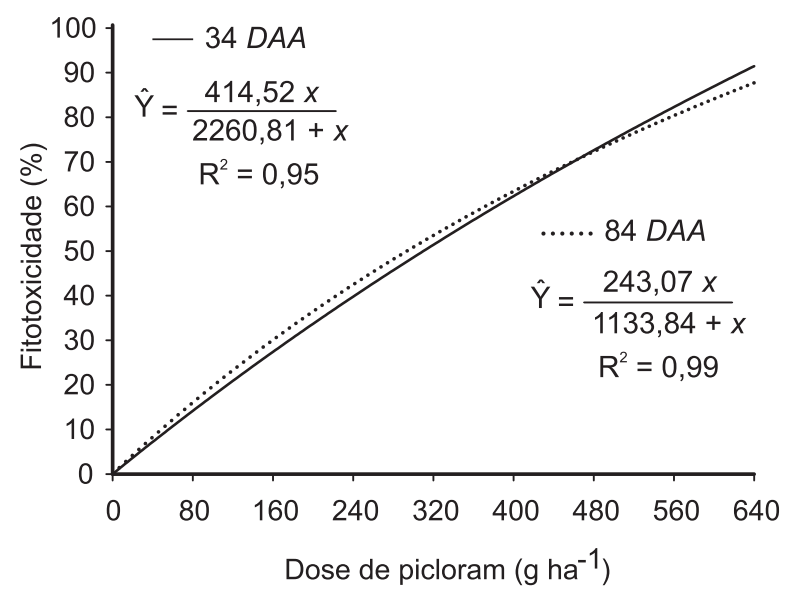

Pennisetum purpureum x Pennisetum glaucum capim-elefante (cv. Paraíso)

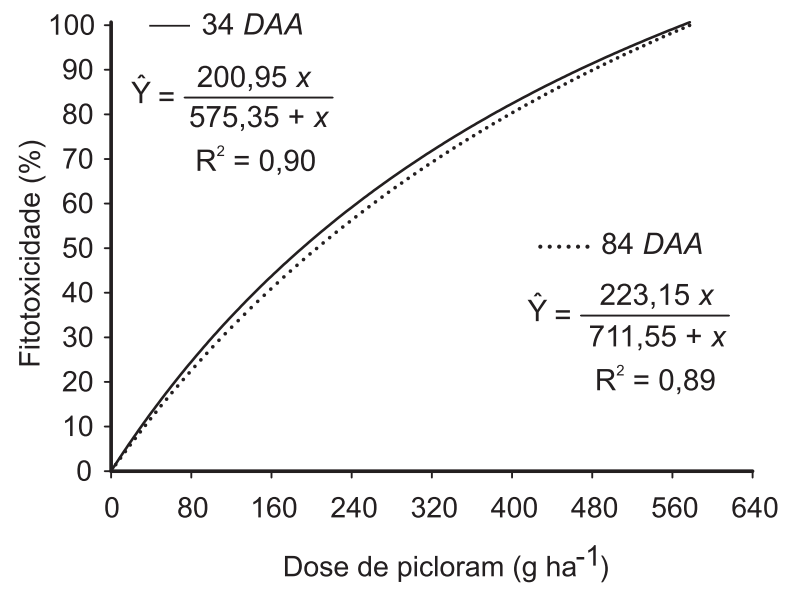

Panicum glaucum - milheto (cv. ADR-300)

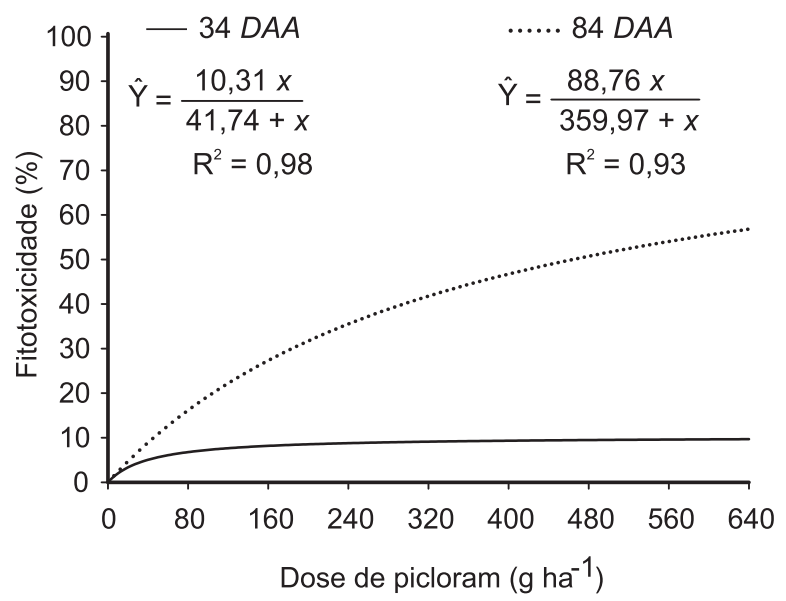

Figura 2 - Fitotoxicidade em plantas cultivadas em solo contaminado com diferentes níveis do herbicida picloram. Rio Verde, 2006. 
Pennisetum glaucum - milheto (cv. ADR-500)

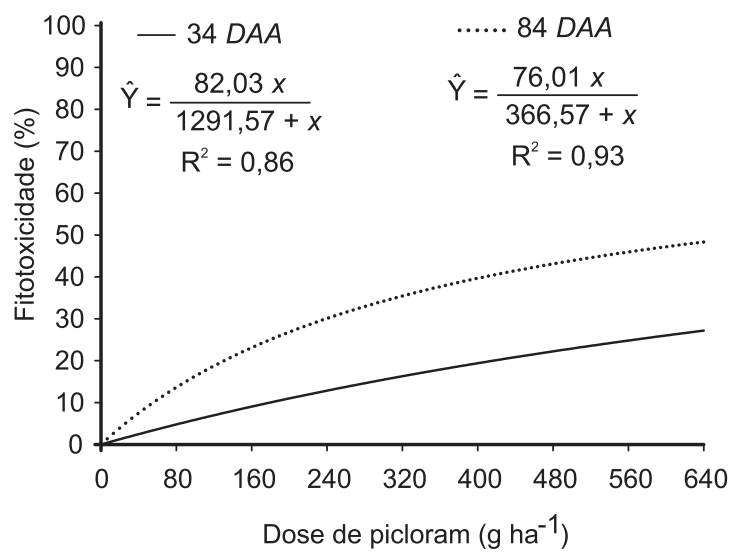

\section{Sorghum bicolor $x$ Sorghum sudanense - sorgo (cv. Jumbo)}

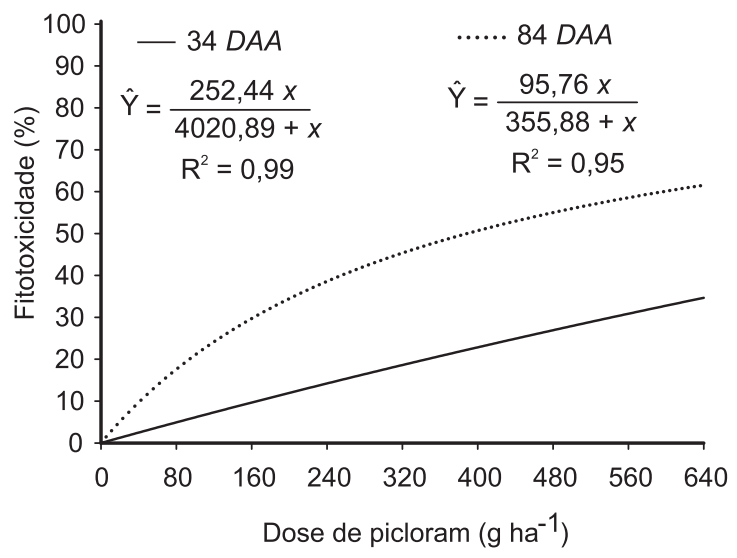

Zea mays - milho (híbrido Coodetec 208)

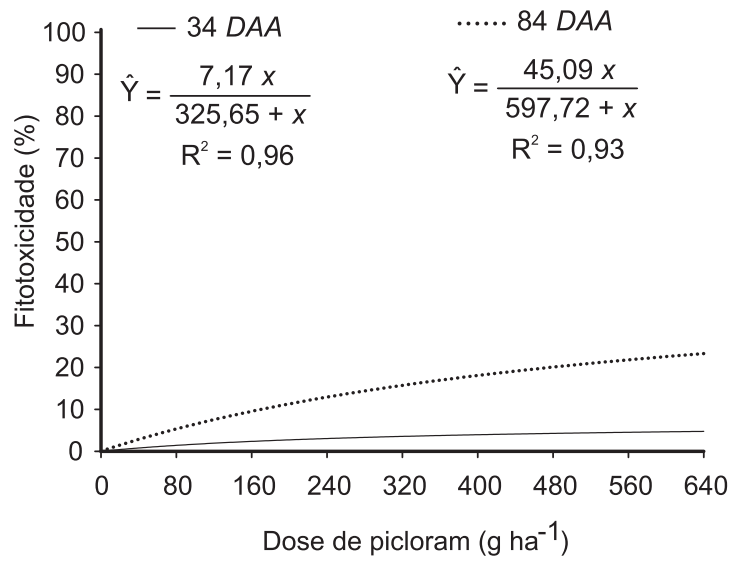

Sorghum bicolor $x$ Sorghum sudanense Cover Crop

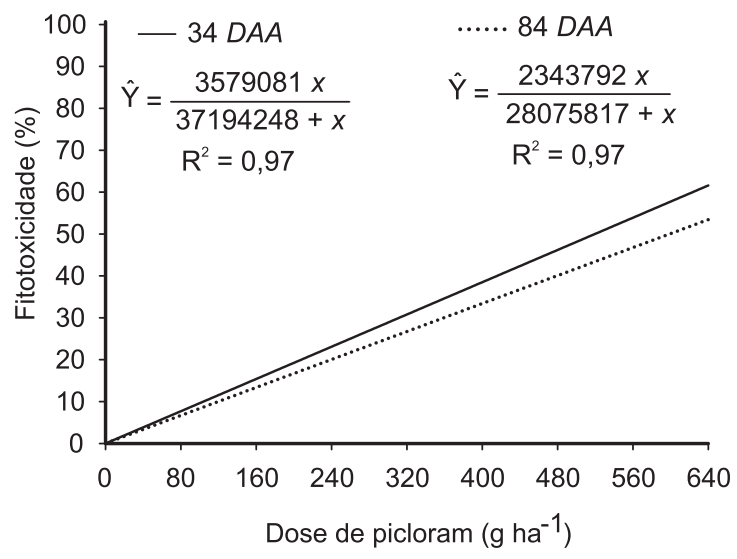

Paspalum atratum - capim-pojuca

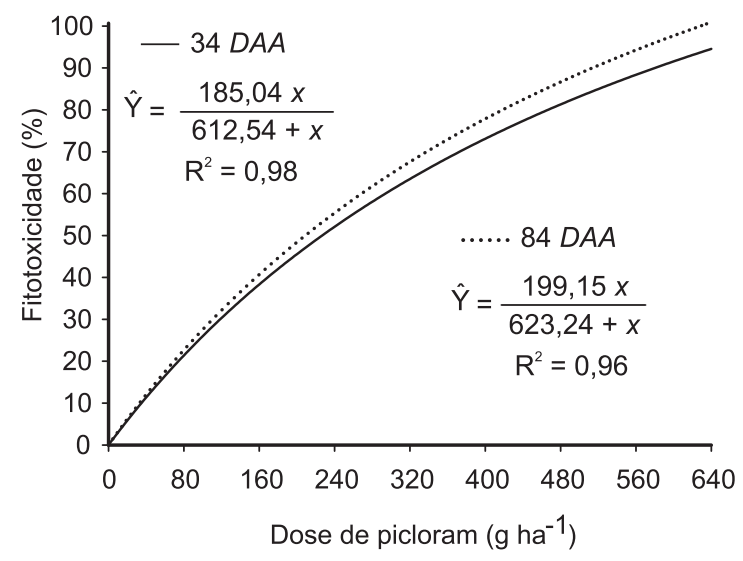

Canavalia ensiformis - feijão-de-porco

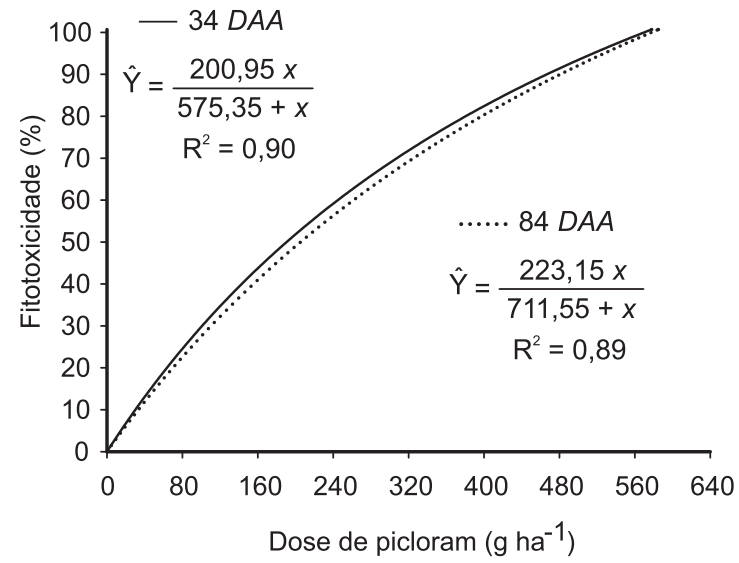

Figura 3 - Fitotoxicidade em plantas cultivadas em solo contaminado com diferentes níveis do herbicida picloram. Rio Verde, 2006. 


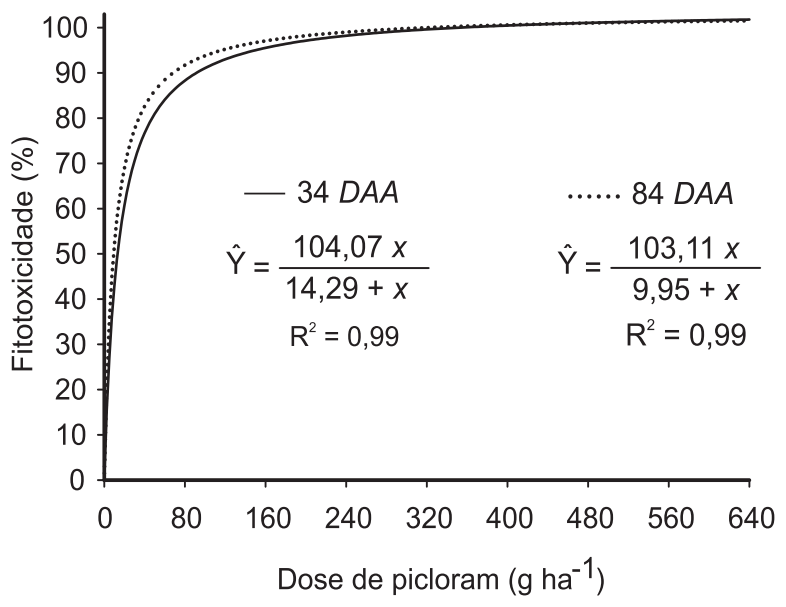

Figura 4 - Fitotoxicidade em plantas de Stizolobium aterrimum - mucuna-preta cultivadas em solo contaminado com diferentes níveis do herbicida picloram. Rio Verde, 2006.

A evolução dos sintomas das plantas de milheto pertencentes ao cultivar ADR-300 foi mais intensa quando comparada à observada no cultivar ADR-500, sendo a fitotoxicidade aos 84 DAA, quando esses cultivares foram submetidos ao solo que recebeu $640 \mathrm{~g} \mathrm{ha}^{-1}$ do herbicida, pouco maior nas plantas do primeiro (Figuras 2 e 3). Também, verificou-se que a dose máxima do picloram aplicado ao solo foi menor para o cultivar ADR-300 (234,3 $\left.\mathrm{g} \mathrm{ha}^{-1}\right)$, em relação à determinada para o cultivar ADR$500\left(312,8 \mathrm{~g} \mathrm{ha}^{-1}\right)$.

Entre os cultivares provenientes do cruzamento de Sorghum bicolor com Sorghum sudanense, o Jumbo apresentou maior intensificação dos sintomas de fitotoxicidade verificados aos 34 DAA, quando comparado ao cultivar Cover Crop, onde se verificou a manutenção inicial dos sintomas ao longo do tempo (Figura 3). Também, menor intoxicação final foi detectada nas plantas de Cover Crop em relação às de Jumbo, quando cultivadas em solo que recebeu $640 \mathrm{~g}$ ha ${ }^{1}$ de picloram. O limite de fitotoxicidade aceitável ocorreu nas doses de 419,3 e 205,0 $\mathrm{g} \mathrm{ha}^{-1}$ do herbicida, respectivamente para Cover Crop e Jumbo. Phillips \& Feltner (1972) observaram alta sensibilidade de plantas de Sorghum bicolor à presença de picloram em dois tipos de solo.

As plantas de capim-pojuca não demonstraram capacidade de superação das injúrias acarretadas pelo residual do picloram no solo. Mortalidade quase que total das plantas de capim-pojuca foi constatada quando seu cultivo foi realizado em solo que recebeu $640 \mathrm{~g} \mathrm{ha}^{-1}$ do herbicida (Figura 3). A dose de $132,9 \mathrm{~g} \mathrm{ha}^{-1}$ de picloram pulverizado ao solo foi a que ocasionou a máxima intoxicação aceitável das plantas dessa espécie.

Na avaliação realizada aos 34 DAA, observou-se pequena evolução dos sintomas de fitotoxicidade, provocados pela ação do picloram, em plantas de milho, os quais se intensificaram um pouco mais na segunda avaliação (84 DAA); contudo, mesmo nos maiores níveis de contaminação desse herbicida no solo, permaneceram em níveis aceitáveis (Figura 3 ). Tanto que o intervalo avaliado das doses de picloram não foi suficiente para se determinar qual a dose que proporcionaria nivel intoxicação das plantas de milho de 35\%. Das espécies testadas, o milho tem a maior representatividade em termos de importância agrícola. De acordo com os resultados, essa espécie suportou melhor os maiores niveis de picloram no solo. Isso representa também, além da possibilidade de continuação de seus estudos em programas de fitorremediação desse herbicida, menores riscos de problemas de carryover quando da transformação de uma pastagem que recebeu aplicações de picloram em uma lavoura de milho. Entretanto, os dados se referem a apenas um híbrido de milho (Coodetec 208), sendo necessários mais resultados para suportar tal hipótese. Ragab (1975) constatou que as culturas de milho e aveia conseguem se desenvolver normalmente em solos que apresentam 2 ppm de picloram.

Pela análise das Figuras 3 e 4, observa-se que as plantas da leguminosa feijão-de-porco toleraram melhor a presença do picloram no solo quando este se encontrava em niveis mais baixos, em relação às plantas de mucunapreta. Esse fato é corroborado pela determinação das doses máximas do herbicida que resulte em intoxicação aceitável - 132,4 $\mathrm{g}^{\text {ha }}{ }^{-1}$ para feijão-de-porco e $5,1 \mathrm{~g} \mathrm{ha}^{-1}$ para mucunapreta-, comprovando a elevada suscetibilidade desta última leguminosa ao residual de picloram no solo. Vanden Born (1969) encontrou efeitos tóxicos da presença de picloram em solos sobre plantas da espécie leguminosa alfafa até cinco anos após sua aplicação.

Após análise dos resultados, constatou-se que as espécies Zea mays - milho (híbrido 
Coodetec 208), Sorghum bicolor x Sorghum sudanense - Cover Crop, Eleusine coracana capim-pé-de-galinha-gigante, Brachiaria brizantha (cv. MG-5 Vitória), Pennisetum glaucum - milheto (cv. ADR-500), Brachiaria decumbens, Brachiaria ruziziensis, Brachiaria humidicola, Pennisetum glaucum - milheto (cv. ADR-300), Brachiaria brizantha (cv. Mulato), Sorghum bicolor x Sorghum sudanense - sorgo (cv. Jumbo), Panicum maximum (cv. Tanzânia), Panicum maximum (cv. Mombaça) e Panicum maximum (cv. Massai) apresentaram fitotoxicidade aceitável quando cultivadas em solo que recebeu doses de picloram superiores a pelo menos metade da dose comercial de aplicação desse herbicida em pastagens (160 $\left.\mathrm{g} \mathrm{ha}^{-1}\right)$. Diante disso, essas espécies podem ser inseridas inicialmente para avaliação em programas de fitorremediação desse herbicida.

Os resultados demonstram que, mesmo sendo o picloram um herbicida recomendado para controle de folhas largas, algumas gramineas são extremamente sensiveis a ele, inclusive espécies utilizadas como pastagens, onde o herbicida apresenta registro para uso. Talvez não seja segura a forma como se vem praticando o registro de herbicidas - de forma geral, "registrado para uso em pastagens" - mas esse registro deveria ser para uso em determinada espécie forrageira, ou mesmo para determinado cultivar.

\section{LITERATURA CITADA}

BOVEY, R. W.; SCIFRES, S. J. Residual characteristics of picloram in grassland ecosystems. Texas Agric. Exp. Sta. Bull., v. B-1111, 24 p. 1971

BUTLER, T. J.; MUIR, J. P.; DUCAR, J. T. Response of coastal bermudagrass (Cynodon dactylon) to varios herbicides and weed control during establishment. Weed Technol., v. 20, n. 4, p. 934-941, 2006.

CHENG, H. H. Extraction and colorimetric of picloram in soil. J. Agric. Food Chem., v. 17, n. 6, p. 1174-1177, 1969.

CORSEUIL, H. X.; MORENO, F. N. Phytoremediation potential of willow trees for aquifers contaminated with ethanol-blended gasoline. Water Res., v. 35, n. 12, p. 30133017,2001

DOWLER, C. C.; WRIGHT, D. L. Weed management systems for pearl millet in the southesstern United States. In: NATIONAL GRAIN PEARL MILLETS, 1., 1995, Tifton. Proceedings... [S.I.] Tifton: University of Georgia, 1995. p. 64-71
FERREIRA, L. R. et al. Seleção de espécies com potencial de remediação de solos contaminados com os herbicidas triclopyr e 2,4-D + picloram. In: CONGRESSO BRASILEIRO DA CIÊNCIA DAS PLANTAS DANINHAS, 25., Brasília. Anais... Brasília: 2006. p. 228.

FREITAS, F. C. L. et al. Eficiência do triclopyr no controle de plantas daninhas em gramado (Paspalum notatum).

Planta Daninha, v. 21, n. 1, p. 159-164, 2003

JOHNSEN, T. N.; MORTON, H. L. Long-term tebuthiuron content of grasses and shrubs on semiarid rangelands. $\mathbf{J}$.

Range Manag., v. 44, n. 3, p. 249-253, 1991

MEYER, R. E.; BOVEY, R. W. Tebuthiuron formulation and placement effects on response of woody plants and soil residue. Weed Sci., v. 6, n. 1, p. 73-378, 1988

NEWMAN, L. A. et al. Phytoremediation of organic contaminants: A review of phytoremediation research at the University of Washington. J. Soil Contam., v. 7, n. 4, p. $531-542,1998$

PHILLIPS, W. M.; FELTNER, K. C. Persistence and movement of picloram in two Kansas soils. Weed Sci., v. 20, n. 1, p. $110-116,1972$.

PIRES, F. R. et al. Seleção de plantas tolerantes ao tebuthiuron e com potencial para fitorremediação. R. Ceres, v. 50, n. 291, p. 583-594, $2003 \mathrm{a}$.

PIRES, F. R. et al. Fitorremediação de solos contaminados por herbicidas. Planta Daninha, v. 21, n. 2, p. 335-341, $2003 b$.

PIRES, F. R. et al. Seleção de plantas com potencial para fitorremediação de tebuthiuron. Planta Daninha, v. 21, n. 3, p. $451-458,2003 \mathrm{c}$.

PIRES, F. R. et al. Inferências sobre atividade rizosférica de espécies com potencial para fitorremediação do herbicida tebuthiuron. R. Bras. Ci. Solo, v. 9, n. 4, p. 627-634, 2005a.

PIRES, F. R. et al. Fitorremediação de solos contaminados com tebuthiuron utilizando-se espécies cultivadas para adubação verde. Planta Daninha, v. 23, n. 4, p. 711-717, $2005 b$.

PIRES, F. R. et al. Adubos verdes na fitorremediação de solos contaminados com o herbicida tebuthiuron. Caatinga, v. 19, n. 1, p. 92-97, 2006

PROCÓPIO, S. O. et al. Seleção de plantas com potencial para fitorremediação de solos contaminados com o herbicida trifloxysulfuron-sodium. Planta Daninha, v. 22, n. 2, p. $315-322,2004 a$. 
PROCÓPIO, S. O. et al. Sensibilidade de cultivares de feijão ao herbicida trifloxysulfuron-sodium. R. Ceres, v. 51, n. 298 , p. $693-706,2004 b$.

PROCÓPIO, S. O. et al. Fitorremediação de solo contaminado com trifloxysulfuron-sodium por mucuna-preta (Stizolobium aterrimum). Planta Daninha, v. 23, n. 4, p. 719-724, 2005a.

PROCÓPIO, S. O. et al. Potencial de espécies vegetais para a remediação do herbicida trifloxysulfuron-sodium. Planta Daninha, v. 23, n. 1, p. 9-16, 2005 b.

PROCÓPIO, S. O. et al. Fitorremediação de solo contaminado com trifloxysulfuron sodium por diferentes densidades populacionais de feijão-de-porco (Canavalia ensiformis (L). DC.). Ci. Agrotecnol., v. 30, n. 3, p. 444449, 2006.

PROCÓPIO, S. O. et al. Development of bean plants in soil contaminated with trifloxysulfuron-sodium after Stizolobium aterrimum and Canavalia ensiformis cultivation. Planta

Daninha, v. 25, n. 1, p. 87-96, 2007.

RAGAB, M. T. H. Residues of picloram in soil and their effects on crops. Can. J. Soil Sci., v. 55, n. 1, p. 55-59, 1975.

SANTOS, J. B. et al. Fitorremediação do herbicida trifloxysulfuron-sodium. Planta Daninha, v. 22, n. 2, p. 223-330, 2004a.

SANTOS, J. B. et al. Seletividade do herbicida trifloxysulfuron sodium para fins de fitorremediação

R. Ceres, v. 51, n. 1, p. 129-141, 2004 b.
SANTOS, E. A. et al. Fitoestimulação como processo de descontaminação de solos com trifloxysulfuron-sodium. In: CONGRESSO BRASILEIRO DA CIÊNCIA DAS PLANTAS DANINHAS, 25., 2006, Brasília. Anais... Brasília: Sociedade Brasileira da Ciência das Plantas Daninhas, 2006. p. 142.

SANTOS, J. B. et al. Fitorremediação de áreas contaminadas por herbicidas. In: SILVA, A.A.; SILVA, J. F. (Eds.). Tópicos em manejo de plantas daninhas. Viçosa, $\mathrm{MG}$ :

Universidade Federal de Viçosa, 2007. 367 p.

SCRAMIN, S.; SKORUPA, L. A.; MELO, I. S. Utilização de plantas na remediação de solos contaminados por herbicidas - levantamento da flora existente em áreas de cultivo de cana-de-açúcar. In: MELO, I. S. et al. Biodegradação. Jaguariúna: Embrapa Meio Ambiente, 2001. p. $369-371$.

SILVA, J. F.; BUENO, C. R. Tolerância de leguminosas de cobertura do solo a herbicidas. In: CONGRESSO BRASILEIRO DA CIÊNCIA DAS PLANTAS DANINHAS, 22., 2000, Foz do Iguaçu. Resumos... Foz do Iguaçu: Sociedade Brasileira da Ciência das Plantas Daninhas, 2000. p. 375 .

SILVA, L. L. et al. Seleção de espécies tolerantes aos herbicidas triclopyr e 2,4-D + picloram. In: CONGRESSO BRASILEIRO DA CIÊNCIA DAS PLANTAS DANINHAS, 25., 2006, Brasília. Anais... Brasília: 2006. p. 230 .

SUSARLA, S.; MEDINA, V. F.; McCUTCHEON, S. C. Phytoremediation: an ecological solution to organic chemical contamination. Ecol. Eng., v. 18, p. 647-658, 2002.

VANDEN BORN, W. H. Picloram residues and crop production. Can. J. Plant. Sci., v. 49, n. 628-629, 1969. 